\title{
Actualización sobre COVID-19 y posible manejo de sus complicaciones sistémicas graves con células troncales mesenquimales
}

\author{
Update on COVID-19 and possible management of its severe \\ systemic complications with mesenchymal stem cells
}

Juan Carlos López Lastra,* Carlos Acosta Behrends, ${ }^{\ddagger}$ Juan Carlos López Noriega ${ }^{\S}$

\section{RESUMEN}

La progresión de la infección de COVID-19 a síndrome de insuficiencia respiratoria aguda (SIRA-CoV-19) depende de una hiperactivación del sistema inmunológico con el fin de eliminar al virus, la cual produce una respuesta inflamatoria exagerada conocida como, «tormenta citoquínica», afectando inicialmente al pulmón; la cual, si no se controla provocará citoquinemia, falla orgánica múltiple y la muerte. Esta respuesta es considerada inmunopatológica por su capacidad cíclica e inflamatoria generando un círculo vicioso, que está caracterizado por el aumento en la producción de factores proinflamatorios. Dentro de las propiedades terapéuticas de las células mesenquimales destacan sus propiedades inmunomoduladoras y antiinflamatorias. Se ha demostrado que pueden tener un efecto importante previniendo o disminuyendo la tormen-

\section{ABSTRACT}

The progression of COVID-19 infection to an acute respiratory failure syndrome (SIRA-CoV-19) depends on the hyper activation of the immune system in order to eliminate the virus, which produces an exaggerated inflammatory response known as, "cytokine storm", initially affecting the lung; if it is not controlled, will cause cytokinemia, multiple organ failure, and death. This response is considered immunopathological due to its cyclical and inflammatory capacity, generating a vicious circle, which is characterized by an increase in the production of pro-inflammatory factors. Among the therapeutic properties of mesenchymal cells, its immunomodulatory and anti-inflammatory properties stand out. It has been shown that they can have a significant effect in preventing or decreasing cytokine

\footnotetext{
* Cirujano Maxilofacial. Profesor de la Facultad de Odontología, UNAM. México.

‡ Cirujano Maxilofacial. Práctica privada Médica Sur y Profesor de División de Estudios de Postgrado e Investigación (DEPel) en Odontología, UNAM. México.

$\S$ Cirujano Maxilofacial. Práctica privada Hospital Ángeles Pedregal. México.
} 
ta de citoquinas a través de la secreción de substancias antiinflamatorias potentes y regulando la respuesta inflamatoria pulmonar. Disminuyendo así la necesidad de ventilación mecánica asistida y reduciendo los pacientes en las terapias intensivas.

Palabras clave: COVID-19, SIRA, células troncales mesenquimales, tormenta citoquínica, inmunomodulación.

\section{INTRODUCCIÓN}

Desde el primer caso detectado infectado con SARSCoV-2 en Wuhan, China en diciembre de 2019, el mundo de la investigación ha comenzado a estudiar diversos métodos para la estabilización y posible cura de los pacientes infectados con dicho virus. En este artículo nos referiremos al agente causal (virus) como SARS-CoV-2, a la enfermedad provocada por este virus como COVID-19 y a la complicación de esta enfermedad como SIRA-CoV-19 (síndrome de insuficiencia respiratoria aguda-COVID-19). ${ }^{1,2}$

Para nadie es nuevo que el virus se ha esparcido de una manera incontrolable por el mundo en el que actualmente los países con mayor número de infectados son China, España, Italia, Estados Unidos, Brasil y México dando alcance hasta 135 países. ${ }^{3}$ Información hasta el 24 de mayo del 2020 la OMS reporta que existen $5,788,071$ casos confirmados con 357,400 muertes y $2,497,132$ casos curados, lo que alcanza una mortalidad del $6.1 \%{ }^{4}$

Por su patogénesis la letalidad es más elevada en sujetos mayores de 60 años de edad, y son aún más susceptibles, los pacientes que cursan con diversas comorbilidades como hipertensión arterial, diabetes mellitus tipo 2, obesidad o inmunodeprimidos. Estas comorbilidades en México tienen una elevada incidencia, y esto explica la letalidad observada en pacientes COVID-19 positivos hasta del $17 \%$ en este subgrupo, mientras que el promedio del grupo total en el mundo es de $7.7 \%$.

La prevalencia de diabetes por diagnóstico médico en México en 2016 fue de $9.4 \% .{ }^{5}$ El $72.5 \%$ de los adultos en México tienen sobrepeso u obesidad, mientras que en el caso de los niños la cifra es de $37.7 \% .^{5,6}$

Desafortunadamente este virus cuenta con algunas particularidades como los son:

a) Es de muy fácil contagio.

b) Puede ser transmitido por pacientes asintomáticos. storm through the secretion of potent anti-inflammatory substances and regulating the pulmonary inflammatory response. Thus decreasing the need for assisted mechanical ventilation and reducing patients in intensive care units.

Keywords: COVID-19, SIRA, mesenchymal stem cells, cytokine storm, immunomodulation.

c) En un porcentaje de los pacientes contagiados el virus se expresa de una forma severa teniendo que hospitalizar a estos pacientes incluso en terapia intensiva.

d) La tasa de mortalidad está lejos de ser insignificante. ${ }^{7}$

El presente manuscrito tiene como objetivo presentar una actualización sobre el manejo de SIRA-CoV-19 con células troncales mesenquimales, así como una actualización sobre la fisiopatología, características clínicas, laboratorios, diagnóstico e imagenología de la enfermedad.

\section{FISIOPATOLOGÍA}

Muchos reportes en la literatura mencionan que el primer paso de la fisiopatología del COVID-19 es que el virus, a través de su proteína de espiga o spike reconoce específicamente al receptor I convertidor de angiotensina II (ECA2). ${ }^{8}$ El receptor ECA 2 se encuentra en una gran cantidad de células en el cuerpo humano, principalmente en las células alveolares tipo II del pulmón y en células endoteliales. Así mismo podemos encontrar dicho receptor en la médula ósea, ganglios linfáticos, timo y bazo, lo que hace al virus infectar esta gran cantidad de órganos. De manera interesante las células inmunológicas como los linfocitos $\mathrm{T}$ y $\mathrm{B}$ y los macrófagos carecen de receptor ECA $2 .{ }^{9}$

Además, un equipo de investigación de Alemania reveló que la proteasa celular serina TMPRSS2 para la preparación de la proteína spike HCoV-19 también es esencial para la entrada y propagación de la célula huésped como en otros coronavirus. ${ }^{10}$

La progresión de la enfermedad depende directamente del sistema inmune del paciente, cuando el sistema inmune se encuentra sobreactivado con el fin de eliminar al virus, se producen una gran cantidad de factores proinflamatorios, lo que conlleva a una tormenta citoquínica, que si persiste se producirá posteriormente falla orgánica múltiple y la muerte. ${ }^{11}$

En el $80 \%$ de la población la resolución de la enfermedad se hará con medidas de aislamiento, sin 
embargo, el grupo en donde el paciente puede llegar a depender de la ventilación mecánica es la principal preocupación, primero por la poca cantidad de ventiladores que existen disponibles para la enfermedad, así como el tiempo que se prevé que van a ser utilizados para asumir mayores compromisos en futuros pacientes. Es decir, estos pacientes ya desarrollaron daño pulmonar conocido como SIRA-COVID-19.

Actualmente es bien conocido que entre los pacientes con enfermedad severa de COVID-19 debido a la progresión de la tormenta citoquínica se producen coagulopatías. Las infecciones virales provocan una respuesta inflamatoria sistémica que a su vez generan un desbalance entre los mecanismos hemostáticos procoagulantes y anticoagulantes. ${ }^{12}$ Durante este proceso, múltiples mecanismos patogénicos están involucrados, como los son la disfunción endotelial, elevación del factor von Willebrand, activación del receptor tipo Toll y la activación de la vía del factor tisular. ${ }^{12-14}$

Algunos reportes de pacientes infectados con SARS-CoV-2 reportan con frecuencia presencia de trombocitopenia en $36.2 \%$ y pueden tener dímero-D elevado en $46.4 \%$ y éstos se elevan en pacientes con COVID- 19 severo en 57.7 y $59.6 \%$ respectivamente.

Este cambio tanto en las plaquetas como en las células endoteliales y las células de la inmunidad innata se da porque estas células exponen su molécula transmembrana fosfatidilserina, la cual se adhiere a las paredes del endotelio vascular pulmonar (microcirculación) que expresa el factor tisular, el cual activa al factor VII de la coagulación en VIIa; este complejo factor tisular-factor VIla activan a los factores de coagulación IX y X, permitiendo la activación de la fibrina; lo que activa la vía extrínseca de la cascada de la coagulación. ${ }^{15,16}$ Lo que explica que los pacientes con enfermedad severa infectados por este nuevo coronavirus corren el riesgo de desarrollar coagulación intravascular diseminada (CID).

El aumento de los niveles de productos de degradación del dímero $\mathrm{D}$ y la fibrina, y el tiempo prolongado de protrombina se han asociado con un mal pronóstico en pacientes afectados por el nuevo coronavirus. ${ }^{16}$

\section{CARACTERÍSTICAS CLÍNICAS}

Normalmente los síntomas de los pacientes infectados con SARS-CoV-2 se presentan aproximadamente cinco días posterior al periodo de incubación, mientras que el periodo entre el inicio de los síntomas y la muerte (en los pacientes que así lo presentaron) varió entre los días 6 y 41 con un media del día $14 .{ }^{17}$
Se ha encontrado que el periodo de inicio de los síntomas es dependiente a la edad del paciente. Los síntomas más comunes que presentan los pacientes infectados con el virus son: fiebre, tos, fatiga, producción de esputo, cefalea, hemoptisis y síntomas gastrointestinales, como lo son diarrea y vómito. Entre los otros síntomas encontrados en menor porcentaje se encuentran: mareos, rinorrea, temblores, fatiga, anorexia, mialgia y dolor abdominal. ${ }^{18,19}$

A diferencia de las manifestaciones de otros betacoronavirus el COVID-19 presenta características clínicas específicas de esta enfermedad como son la rinorrea, estornudos, anosmia y dolor de garganta. ${ }^{20,21}$

Generalmente las características radiográficas de COVID-19 son similares a las encontradas en las imágenes vistas en neumonías adquiridas en la comunidad causadas por otros microorganismos. ${ }^{22}$ La mayoría de los estudios actuales recomienda el uso de la tomografía computarizada para el diagnóstico de este tipo de neumonías, la mayoría de las imágenes observadas en pacientes positivos para COVID-19 muestran predominantemente opacidades tipo vidrio esmerilado (65\%), consolidaciones (50\%), engrosamiento irregular septal interlobular (35\%), broncograma aéreo (47\%) y engrosamiento de la pleura adyacente (32\%), involucrando predominantemente el lóbulo inferior y la periferia. ${ }^{23}$

\section{LABORATORIOS}

Los niveles de biomarcadores pueden cambiar acorde con la severidad de la infección por SARSCoV-2, la infección por SARS-CoV-2 provoca unos cambios hematológicos severos, empezando por trombocitopenia. ${ }^{24}$

Los cambios en los resultados de laboratorio predominantemente se dan con una hipoalbuminemia, marcadores inflamatorios elevados, como la proteína $\mathrm{C}$ reactiva (PCR), lactato deshidrogenasa (LDH), y la velocidad de sedimentación eritrocitaria (VSE), entre otros. ${ }^{25}$

La linfopenia es claramente asociada con la severidad de la enfermedad, los pacientes que han muerto por COVID-19 han tenido una significativa disminución en el conteo linfocitario a diferencia de los sobrevivientes. De hecho, la estabilización de los linfocitos puede ser un factor importante para la recuperación. Otras células sanguíneas que disminuyen importantemente son los neutrófilos, eosinófilos, plaquetas y CD8+ y son factores que provocan que la enfermedad vaya de moderada a severa en COVID19. El factor estimulador de colonias granulocíticas 
(G-CSF) se ha encontrado elevado en pacientes de la UCI (Unidad de Cuidados Intensivos) y significativamente asociado con la severidad de la enfermedad. ${ }^{26}$

La frecuencia de linfopenias encontradas sugieren que el SARS-CoV-2 puede actuar en los linfocitos, especialmente linfocitos T, como se ve en SIRACoV-19, quizá incluyendo la depleción de células CD4+ y CD8+. ${ }^{26}$ El factor de necrosis tumoral alfa (TNF- $\alpha$ ), la proteína inducida por interferón 10 (IP10), la proteína 1 quimioatrayente de monocitos (MCP-1), la quimiocina C-C motif, el ligando 3 (CCL-3) y distintas interleucinas (IL-2, IL-6, IL-7) fueron significativamente asociadas con la severidad de la enfermedad y particularmente observadas en los casos admitidos en la UCI.

Aparentemente los niveles séricos de algunas interleucinas tienen el potencial de definir entre enfermedad moderada y severa, y posiblemente pueden ser usadas como marcadores de pronóstico. ${ }^{26}$

En el pulmón, como resultado de la tormenta citoquínica se acumulan concentraciones importantes de TNF- $\alpha$, IL-1 beta e interferón gamma. Su actividad proinflamatoria termina por dañar más el endotelio vascular pulmonar, genera edema intersticial entre el endotelio y el alveolo, el cual acumula también importantes cantidades de edema, dificultando así el intercambio gaseoso de oxígeno y dióxido de carbono. ${ }^{12}$

El uso de proteína $C$ reactiva en pacientes con COVID-19 ha demostrado por los estudios retrospectivos de Wuhan, China, que la mayoría de los pacientes con enfermedad severa mostraron significativamente altos niveles de proteína $C$ reactiva en comparación con los no severos $(57.9 \mathrm{mg} / \mathrm{L}$ versus $33.2 \mathrm{mg} / \mathrm{L}$ ). Los niveles de proteína $\mathrm{C}$ reactiva son un fuerte indicador que refleja la presencia y severidad de COVID-19. La proteína C reactiva es uno de los primeros biomarcadores en el torrente sanguino que cambia al reflejar complicaciones fisiológicas. ${ }^{24}$

Los niveles de LDH son mayores en pacientes en la $\mathrm{UCl}$ que los que no entraron a la $\mathrm{UCl}(248$ $\mathrm{U} / \mathrm{L}$ versus $151 \mathrm{U} / \mathrm{L}$ ). Hay suficiente evidencia que correlaciona la extensión del daño tisular y la inflamación con el incremento de los niveles de LDH. ${ }^{24}$ Las investigaciones han encontrado que la media de los niveles de dímero $D$ en pacientes ingresados en la $\mathrm{UCl}$ son notablemente mayores que los que no $(2.4 \mathrm{mg} / \mathrm{L}$ versus $0.5 \mathrm{mg} / \mathrm{L}) .{ }^{24}$ Aquellos pacientes con infección severa de COVID-19 tienen una menor cantidad de plaquetas $\left(\leq 31 \times 10^{9} / L\right)$ y los pacientes que murieron aún menor conteo de plaquetas. ${ }^{24}$

La combinación de las pruebas de laboratorio y las imágenes de tomografía es la mejor combinación para adquirir un diagnóstico preciso y temprano. Se han diagnosticado pacientes asintomáticos con imágenes tomográficas de tórax, iniciando con imágenes opacas en forma de vidrio esmerilado unilaterales focalizadas que avanzan hacia bilaterales y llegan a la consolidación entre las semanas uno y tres. ${ }^{27}$

Un examen de rutina de sangre, prueba de reacción en cadena de polimerasa, TC de tórax, función de la coagulación, gases arteriales y pruebas de función tisular deben ser monitorizados en estos pacientes. ${ }^{28}$

\section{DIAGNÓSTICO}

El diagnóstico de COVID-19 se basa en las manifestaciones clínicas y en exámenes auxiliares de detección de ácido nucleico, tomografía de tórax, identificación inmune tecnológica y hemocultivo. ${ }^{29}$ Los pacientes infectados por SARS-CoV-2 tienen signos y síntomas poco característicos incluyendo síntomas respiratorios, tos, fiebre, disnea y neumonía viral. Por lo que los estudios auxiliares son necesarios para el diagnóstico del COVID-19, así como para la historia epidemiológica. ${ }^{1}$

Para establecer el diagnóstico es suficiente con las características clínicas, imágenes tomográficas y la prueba de reacción de polimerasa en cadena en tiempo real (RT-PCR) como referencia estándar. Acorde con la Comisión Nacional de Salud de China y la OMS, los criterios de diagnósticos son los siguientes: ${ }^{25}$

1. Historia de exposición con personas con signos de dificultad respiratorias (que vivan en Wuhan) dos semanas antes de la aparición de síntomas.

2. Síntomas clínicos de fiebre, disminución de leucocitos, reducción de linfocitos, y/o imágenes en CT de tórax.

3. Prueba de RT-PCR positiva a SARS-CoV-2.

El confirmar las imágenes y las características clínicas de neumonía, son indicaciones para la hospitalización. ${ }^{25,28}$

La prueba de detección más común es la RT-PCR basada en el aislamiento del ARN de las muestras tomadas de las vías aéreas con cotonetes en la orofaringe, esputo, aspirado nasofaríngeo, lavado broncoalveolar o aspirado traqueal profundo. ${ }^{28}$

Existen dos métodos para detectar el ácido nucleico comúnmente usadas para el SARS-CoV-2, que son la RT-PCR y la secuenciación de alto rendimiento de todo el genoma. No obstante la aplicación de la 
secuenciación de alto rendimiento en el diagnóstico clínico es limitada por la dependencia de equipo y su alto costo. Entonces la RT-PCR es la más común, efectiva y el método más seguro para detectar los virus patogénicos en las secreciones respiratorias y sangre. Se reporta una sensibilidad de esta prueba de entre el 50 y $79 \%$.

La causa de la baja efectividad de la medición del ácido nucleico viral podría ser por la baja carga viral, una muestra inapropiada, variación de la tasa de diagnóstico entre los diferentes kits y la poca tecnología desarrollada para la detección del ácido nucleico de este virus. Las muestras del tracto respiratorio inferior y el esputo tiene la mayor fracción del genoma y carga viral en comparación de las muestras del tracto superior, los cuales son los óptimos para mejorar la precisión de la prueba. ${ }^{28}$

El rol principal de la citología en el SIRA-CoV-19 es descartar infecciones superpuestas en el esputo y otros especímenes del tracto respiratorio. Las características citológicas en el esputo parecen no ser específicas, y refleja el patrón de la lesión aguda pulmonar subyacente. Éstos consisten en la presencia de un número aumentado de macrófagos, formando una agregación de los mismos, mostrando un cambio citoplasmático, incluyendo la presencia de un citoplasma espumoso o grandes vacuolas citoplásmicas o cambios nucleares, incluyendo multinucleación y núcleo con apariencia de vidrio esmerilado. ${ }^{30}$

Siempre es importante utilizar ciertos especímenes de fluido de lavado bronquial, ya que éste da positivo cuando los especímenes tomados de nasofaringe y orofaringe dan negativo. ${ }^{31}$

A pesar de la sensibilidad de la prueba de RT-PCR existe un rango de falsos negativos que no se pueden ignorar por la severidad de las consecuencias de la falta de diagnósticos en estos casos. Por lo que se ha propuesto el uso de tomografía de tórax como un método diagnóstico necesario por su mayor sensibilidad. Para pacientes con alta sospecha de COVID-19 y prueba de RT-PCR negativa, la tomografía de tórax puede ser de mucha ayuda. ${ }^{1}$

La tomografía (TC) tiene una respuesta más rápida que las pruebas de diagnóstico molecular en un laboratorio estándar, pueden proveer más información detallada relacionada con la patología y es mejor para la medida cuantitativa del tamaño de la lesión y la extensión o severidad en el pulmón, que puede tener implicaciones en el pronóstico. Además con la agudeza de una TC con sistema de inteligencia artificial puede tener el potencial de asistir en un diagnóstico temprano para planeación, monitoreo y tratamiento..$^{32}$ Se ha reportado que las sensibilidad de la tomografía es superior a la de la RT-PCR (98\% versus $71 \%) .{ }^{28}$

\section{RESPUESTA INMUNE Y TORMENTA CITOQUÍNICA}

Clínicamente, la respuesta inmune inducida por el virus se encuentra en dos fases. Durante la incubación y las etapas no severas, se requiere una respuesta inmune adaptativa específica para eliminar el virus y evitar la progresión de la enfermedad a etapas severas. Para el desarrollo de una respuesta inmune protectora endógena en las etapas de incubación y no severa, el huésped debe tener una buena salud general y un fondo genético apropiado (por ejemplo el antígeno leucocitario humano) que genere inmunidad antiviral específica. Se sabe que las diferencias genéticas contribuyen a las variaciones individuales en la respuesta inmune a los patógenos. ${ }^{29} \mathrm{La}$ infección por SARS-CoV-2 puede activar tanto la respuesta inmune innata como la adaptativa. Sin embargo, las respuestas innatas inflamatorias no controladas y las respuestas inmunitarias adaptativas disminuidas pueden conducir a daños nocivos en los tejidos, tanto local como sistémicamente. Los pacientes con COVID-19 severo y en etapas avanzadas usualmente presentan linfopenia con disminución importante de linfocitos T CD4+ y CD8+. Además, los marcadores de agotamiento funcional linfocitario, como NKG2A, en los linfocitos citotóxicos, incluidas las células NK (natural killer) y las células T CD8+, se expresan al alza en pacientes con COVID-19. ${ }^{30,33}$

Sin embargo, cuando se altera una respuesta inmunitaria protectora, el virus se propagará y se producirá una destrucción masiva de los tejidos afectados, especialmente en los órganos que tienen una alta expresión de ECA 2. Las células dañadas inducen inflamación innata en los pulmones que está mediada en gran medida por macrófagos y granulocitos proinflamatorios y si esta respuesta no disminuye o se regula terminará en una tormenta citoquínica. ${ }^{29}$

La progresión de la infección COVID-19 a SIRACOVID-19 depende directamente del sistema inmune del paciente; cuando éste se encuentra sobreactivado con el fin de eliminar al virus, se producen una gran cantidad de factores proinflamatorios lo que conlleva a una "tormenta citoquínica» inicialmente afectando el pulmón desarrollando una neumonía, 
si la evolución de la respuesta inmunopatológica no se detiene, habrá citoquinemia, que si persiste, se producirá posteriormente falla orgánica múltiple y la muerte. ${ }^{34}$

Esta respuesta es considerada inmunopatológica por su capacidad cíclica e inflamatoria generando un círculo vicioso, que está caracterizado por el aumento en la producción de factores proinflamatorios siendo los más frecuentes, dañinos y abundantes, el TNF- $\alpha$, la interleucina (IL-6), el interferón gamma, interleucina 17 (IL-17) y la interleucina 2 (IL-2); todos éstos producidos por neutrófilos, monocitos, pero principalmente por el macrófago polarizado a tipo M1 proinflamatorio y por los linfocitos T citotóxicos activados por la infección por SARS-CoV-2. ${ }^{1,35}$

\section{ROL DE LAS CÉLULAS MESENQUIMALES}

Las células mesenquimales han sido ampliamente utilizadas tanto en investigación básica como en estudios clínicos, su eficacia y seguridad han sido ampliamente reportadas en diferentes patologías inflamatorias inmunorreguladas como enfermedad de huésped contra hospedero y lupus eritematoso sistémico. De igual manera se ha demostrado efectividad en el tratamiento de enfermedades cardiovasculares, hepáticas y renales con células mesenquimales. ${ }^{8}$

A nivel celular, las células mesenquimales parecen tener una inmunidad natural ante el virus debido a sus propiedades inmunomoduladoras, además es conocido que estas células no expresan el receptor ECA2. Así mismo se ha propuesto que pueden tener un efecto importante previniendo o disminuyendo la tormenta de citoquinas a través de la secreción de substancias antiinflamatorias potentes. ${ }^{11}$

Posterior a la infusión de las células mesenquimales por vía endovenosa aproximadamente el $90 \%$ de estas células se alojarán el pulmón, lo que pudiera mejorar importantemente el microambiente pulmonar, proteger a las células alveolares epiteliales, prevenir la fibrosis pulmonar y mejorar la función pulmonar. ${ }^{11,36-38}$

Golchin y cols. mencionan en su publicación que el uso de las células mesenquimales puede ser de mayor beneficio que otras por ciertas cualidades que se enumeran a continuación, I) Son de fácil acceso y se pueden obtener de diversas fuentes, como lo son la médula ósea, tejido adiposo, cordón umbilical, pulpa dental, sangre menstrual, bolsa adiposa de Bichat, etc. II) Son multipotentes; III) Pueden ser expandidas en el laboratorio en adecuada cantidad para su uso clínico en un periodo razonable de tiempo; IV) Pueden ser criopreservadas para su uso repetido con fines terapéuticos; V) En los estudios clínicos en las que han sido utilizadas no han presentado reacciones adversas mayores; VI) Su seguridad y efectividad han sido demostradas en gran cantidad de estudios clínicos. ${ }^{39}$

Si a todo esto sumamos que estas células no expresan el complejo mayor de histocompatibilidad ni tampoco el ECA 2, pudieran ser una alternativa para su uso en pacientes con COVID-19 severo. ${ }^{39}$

\section{MECANISMO DE ACCIÓN DE LAS CÉLULAS TRONCALES MESENQUIMALES}

La terapia intravenosa con células troncales mesenquimales (CTM) puede disminuir la concentración de factores proinflamatorios durante el SIRA-CoV-19 y pueden ser una terapia accesible, ya que las células que se aíslan, expanden y criopreservan no expresan el complejo mayor de histocompatibilidad, son HL-DR negativas pudiendo entonces utilizarse de manera alogénica. ${ }^{35}$

Es importante referirnos al estudio clínico publicado por Weiss, ya que éste es un punto de partida con resultados de seguridad importantes en la administración de CTM alogénicas en pacientes con daño pulmonar; el estudio fue multicéntrico, doble ciego, con controles placebo realizado en Estados Unidos, que permitió mostrar que el uso de las células mesenquimales administradas por vía intravenosa son seguras en los pacientes con enfermedad pulmonar obstructiva crónica (EPOC). ${ }^{40}$

Los pacientes inscritos fueron aleatorizados para recibir un placebo de solución fisiológica y CTM alogénicas no compatibles con HLA (es decir, no se comprobó necesariamente la compatibilidad de las células con cada paciente), obteniendo los siguientes resultados:

1) No hubo toxicidad.

2) No se presentaron efectos adversos serios.

3) No hubo muertes.

4) No hubo exacerbaciones del EPOC.

5) No hubo empeoramiento de la enfermedad. ${ }^{40}$

Muchos reportes científicos indican que las células mesenquimales necesitan ser activadas por un medio ambiente inflamatorio en el huésped para que puedan 
desarrollar y activar sus efectos inmumoduladores y antiinflamatorios. ${ }^{41}$

La presencia de las CTM vivas es temporal y dentro de las primeras 24 horas el $90 \%$ mueren en los pulmones donde secretan su contenido o secretoma que también es distribuido a otros sitios, en particular al hígado; ${ }^{36}$ en el SIRA-CoV-19 el pulmón ya está inflamado, lo cual permite que las CTM activen sus capacidades inmunomoduladoras y antiinflamatorias. La potencial desaparición rápida de las CTM no inhibe su efecto funcional. ${ }^{42}$

Se ha demostrado que la fagocitosis de las CTM muertas induce la generación de macrófagos con un fenotipo antiinflamatorio tipo $2 .^{42} \mathrm{La}$ apoptosis de las CTM induce inmunomodulación mediada por el receptor. Una vez fagocitadas en el pulmón, el segundo paso es la identificación de la célula apoptótica a través de la exposición de la fosfatidilserina en la membrana plasmática de la célula; las CTM son activamente inducidas a la apoptosis dependiente de perforinas secretadas por el macrófago activado en el pulmón. ${ }^{42}$

Los siguientes mecanismos de inmunomodulación han sido descritos para la actividad de las células mesenquimales y las células inmunológicas:

1. Las CTM y la inmunidad innata. Las CTM promueven la polarización de macrófagos M1 proinflamatorios a macrófagos M2 antiinflamatorios y esto es dependiente del contacto celular y de los factores solubles secretados por las CTM: ${ }^{43}$

A) Prostaglandina E2 (PGE2).

B) Catabolitos de la actividad de la indolamina como son: quinurenina y ciclooxigenasa 2 (COX-2).

Esta polarización dada como resultado del efecto de las CTM sobre los macrófagos tipo M2, está relacionada con la habilidad de las CTM en favorecer la emergencia de las células «T reguladoras» (Tregs), que están importantemente involucradas en la inmunosupresión. ${ }^{44}$

2. Las CTM y su efecto inmunológico mediado por las células T. Las CTM tienen la capacidad de suprimir la secreción de factores proinflamatorios por los linfocitos T mediante la secreción de factores solubles que incluyen:

- Factor de crecimiento beta-transformante (FCT-ß).
- Factor de crecimiento hepatocítico $(\mathrm{FCH})$.

- Prostaglandina E 2 (PGE2).

- Indolamina 2,3-dioxigenasa (IDO).

La liberación de los factores supresores aumenta después de que las células mesenquimales son estimuladas por el TNF e Interferón gamma; ambos TNF e interferón gamma están presentes en altas concentraciones en los pulmones de pacientes con SIRA-CoV-19. ${ }^{45}$

3. CTM y células $T$ reguladoras. La incubación in vitro de las CTM humanas con monocitos de la sangre heteróloga, induce la diferenciación del monocito a células CD4+ CD25+ FoxP3+. A estas células se les conoce como células $T$ reguladoras (consideradas en la inmunobiología como las células inmunomoduladoras maestras). ${ }^{43}$

\section{CÉLULAS TRONCALES MESENQUIMALES EN COVID-19/SIRA-COV-19}

Las células mesenquimales juegan un papel importante principalmente por dos vías, las cuales son mediante sus propiedades inmunomoduladoras y su capacidad antiinflamatoria. Estas células son capaces de secretar muchas citoquinas de forma paracrina o pueden tener interacción por contacto directo con las células de sistema inmune incluyendo linfocitos $T$ y $B$, células dendríticas, macrófagos y células NK, logrando así una inmunomodulación. Leng y cols. muestran un diagrama en el cual resumen como las CTM regulan la respuesta inflamatoria y promueven la reparación de los tejidos dañados (Figura 1).8

El primer caso de COVID-19 tratado con células mesenquimales obtenidas del cordón umbilical fue publicado en por Liang y cols. en China, en el cual reportan un caso de una paciente femenina de 65 años de edad la cual se presentaba con neumonía severa, falla respiratoria y falla orgánica múltiple con necesidad de ventilación mecánica además de linfopenia entre otros estudios de laboratorio alterados. ${ }^{46}$

La paciente se trató inicialmente al segundo día con terapia antiviral de lopinavir/ritonavir, inhalación de IFN- $\alpha$ y oseltamivir (se retiró oseltamivir después de una administración), y también inyección intravenosa de moxifloxacina, Xuebijing, metilprednisolona e inmunoglobulina y respondió satisfactoriamente los primeros dos días de tratamiento; sin embargo, entre el día 3 y 4 presentó una recaída tanto en la clínica 
como en estudios de laboratorio. Debido a esto el día 12 de estancia hospitalaria y debido a la falla orgánica múltiple severa (con la guía de un grupo de especialistas) se decidió retirar la terapia antiviral, de corticosteroides y se propuso la terapia con células mesenquimales humanas de cordón umbilical a lo que el paciente y sus familiares estuvieron de acuerdo. ${ }^{46}$

Fueron administradas 50 millones de células en tres diferentes ocasiones (día 14, 17 y 19 intrahospitalarios) por vía intravenosa. Al día siguiente de la segunda dosis administrada, los signos vitales se estabilizaron así como los signos de falla multiorgánica y dejó la ventilación mecánica. A los dos días posteriores a la tercera infusión fue dada de alta de la terapia intensiva y sus laboratorios comenzaron a normalizarse, en este tiempo el frotis de garganta resultó negativo para SARS-CoV-2 y al sexto día posterior a la tercera infusión las imágenes pulmonares de tomografía computarizada presentaban gran mejoría con respecto a las tomadas anteriormente..$^{46}$

En el segundo estudio clínico se estudiaron a 10 pacientes, en el cual siete de los 10 pacientes (1 crítico, 4 severos y 2 moderados) recibieron terapia con CTM y tres pacientes del grupo control (severos) que recibieron placebos. ${ }^{8}$

Ninguno de estos pacientes estaba respondiendo al tratamiento estándar contra la enfermedad. A todos los pacientes se les siguió por 14 días. Los siete pacientes en el grupo tratado CTM resultaron recuperados, mientras que los tres pacientes del grupo control uno falleció, otro presentó síndrome de dificultad respiratoria aguda y el último se mantuvo en estadio severo. De manera interesante 13 días posteriores a la infusión de los pacientes del grupo experimental todos resultaron negativos para el ácido nucleico de SARS-CoV-2 y tampoco reportaron efectos adversos. ${ }^{8}$

En el grupo tratado tan solo unos días posteriores al a infusión de CTM la saturación de oxígeno, los biomarcadores de inflamación y lesión de tejidos como la proteína $C$ reactiva, aspartato aminotransferasa, la actividad de cratinin-cinasa y la mioglobina se normalizaron. También se observaron mejorías significativas en las imágenes de control de tomografía computarizada pulmonar. ${ }^{8}$

En un metaanálisis publicado en el mes de mayo de 2020 en donde se incluyeron estudios controlados aleatorizados, incluyendo más de 200 pacientes, con SIRA-CoV-19 cuyo tratamiento estuvo basado en la terapia celular intravenosa con CTM de diferentes fuentes para reducir la mortalidad provocada por el COVID-19. En este metaanálisis no se reporta ningún evento adverso serio, más allá de fiebre transitoria no relacionada al trasplante. Se reportan mejorías significativas en las TC de tórax y en la disminución

\begin{tabular}{|c|c|c|}
\hline $\begin{array}{l}\text { Patología. Lesión pulmonar: } \\
\text { lesión alveolar difusa con } \\
\text { exudado celular mixoide } \\
\text { Intervención. Agregación } \\
\text { pulmonar, protección de las } \\
\text { células alveolares epiteliales, } \\
\text { mejoría en la fibrosis pulmo- } \\
\text { nar y la función pulmonar }\end{array}$ & \multirow{2}{*}{$\begin{array}{c}\text { Células troncales } \\
\text { mesenquimales } \\
\text { ECA } 2(-)\end{array}$} & $\begin{array}{l}\text { Patología. Falla orgánica } \\
\text { múltiple: las enzimas séricas } \\
\text { muestran un aumento de la } \\
\text { aspartato aminotransferasa } \\
\text { y creatincinasa } \\
\text { Intervención. Promueve la } \\
\text { reparación endógena, me- } \\
\text { jorando el microambiente }\end{array}$ \\
\hline & & \\
\hline $\begin{array}{l}\text { Patología. Agotamiento de la } \\
\text { inmunidad celular: el núme- } \\
\text { ro de células CD4 y CD8T se } \\
\text { ve reducido importantemen- } \\
\text { te pero sobreactivado } \\
\text { Intervención. Remode- } \\
\text { lación de los subtipos y } \\
\text { función de las células de } \\
\text { inmunidad }\end{array}$ & & $\begin{array}{c}\text { Patología. Tormenta cito- } \\
\text { quínica: aumento en los } \\
\text { niveles plasmáticos de IL-2, } \\
\text { IL-7, G-SCF, IP10, MCP-1, } \\
\text { MIP-1 } \alpha \text { y TNF- } \alpha \\
\text { Intervención. Remode- } \\
\text { lación de los subtipos y } \\
\text { función de las células de } \\
\text { inmunidad }\end{array}$ \\
\hline
\end{tabular}

Figura 1.

Modificado de: Leng Z et al. ${ }^{8}$ 
de todos los marcadores inflamatorios. Las pocas muertas reportadas no fueron relacionadas al trasplante de las CTM. La gran mayoría de pacientes que se encontraban intubados en las terapias intensivas sin más ni más sobrevivieron.

Actualmente se encuentran múltiples estudios avalados por la FDA que ya cumplieron con las fases iniciales de seguridad, ${ }^{47-50}$ dichos estudios se pueden encontrar en www.clinicaltrials.gov, ${ }^{51-53}$ por lo que la terapia con células mesenquimales para el tratamiento de COVID-19 se continuará estudiando con un posible futuro prometedor.

\section{CONCLUSIONES}

Con base en los resultados mostrados en todos los artículos aquí referidos y principalmente en el metaanálisis recientemente publicado en la revista Stem Cells Translational and Medicine, podemos concluir que el trasplante de células mesenquimales por vía intravenosa para el tratamiento de SIRA-CoV-19 es seguro.

Varios países han pasado a la fase 2/3 para la valoración del incremento de la dosis y resultados de eficacia; aunque los altos índice de sobrevivencia de los pacientes de SIRA-CoV-19 graves reportados hasta el día de hoy pueden considerarse como resultados eficaces.

El entender la fisiopatología del círculo vicioso generado por la tormenta citoquínica que lleva al paciente no sólo a la neumonía sino a la falla multiorganica y a la muerte, permite entender que el mecanismo de acción de las células mesenquimales por vía intravenosa funciona aun en pacientes con muy mal pronóstico.

\section{BIBLIOGRAFÍA}

1. Li X, Geng M, Peng Y, Meng L, Lu S. Molecular immune pathogenesis and diagnosis of COVID-19. J Pharm Anal. 2020; 10 (2): 102-108.

2. Zhou F, Yu T, Du R, Fan G, Liu Y, Liu Z et al. Clinical course and risk factors for mortality of adult inpatients with COVID-19 in Wuhan, China: a retrospective cohort study. Lancet. 2020; 395 (10229): 1054-1062.

3. https://www.cidrap.umn.edu/covid-19/epidemiology

4. https://www.who.int/emergencies/diseases/novelcoronavirus-2019/situation-reports/

5. Rojas-Martínez R, Basto-Abreu A, Aguilar-Salinas CA, ZárateRojas E, Villalpando S, Barrientos-Gutiérrez T. Prevalencia de diabetes por diagnóstico médico previo en México. Salud Publica Mex. 2018; 60 (3): 224-232.

6. Rivera Dommarco JA, Hernández Ávila M, Aguilar Salinas CA, Vadillo Ortega F, Murayama Rendón C. La obesidad en México. México: Instituto Nacional de Salud Pública; 2020.
7. Cossarizza A, De Biasi S, Guaraldi G, Girardis M, Mussini C; Modena Covid-19 Working Group (MoCo19)\#. SARS-CoV-2, the virus that causes COVID-19: cytometry and the new challenge for Global Health. Cytometry A. 2020; 97 (4): 340-343. doi: 10.1002/ cyto.a.24002.

8. Leng Z, Zhu R, Hou W, Feng $Y$, Yang $Y$, Han $Q$ et al. Transplantation of ACE2- mesenchymal stem cells improves the outcome of patients with COVID-19 pneumonia. Aging Dis. 2020; 11 (2): 216-228.

9. Hamming I, Timens W, Bulthuis ML, Lely AT, Navis G, van Goor $H$. Tissue distribution of ACE2 protein, the functional receptor for SARS coronavirus. A first step in understanding SARS pathogenesis. J Pathol. 2004; 203 (2): 631-637.

10. Hoffmann M, Kleine-Weber H, Krüger N, Müller M, Drosten C, Pöhlmann S. The novel coronavirus 2019 (2019-nCoV) uses the SARS-coronavirus receptor ACE2 and the cellular protease TMPRSS2 for entry into target cells. bioRxiv. 2020; 2020.01.31.929042.

11. Atluri S, Manchikanti L, Hirsch JA. Expanded umbilical cord mesenchymal stem cells (UC-MSCs) as a therapeutic strategy in managing critically ill COVID-19 patients: the case for compassionate use. Pain Physician. 2020; 23 (2): E71-E83.

12. Subramaniam $S$, Scharrer I. Procoagulant activity during viral infections. Front Biosci (Landmark Ed). 2018; 23: 1060-1081.

13. van Gorp EC, Suharti C, ten Cate H, Dolmans WM, van der Meer JW, ten Cate JW et al. Review: infectious diseases and coagulation disorders. J Infect Dis. 1999; 180 (1): 176-186.

14. Key NS, Vercellotti GM, Winkelmann JC, Moldow CF, Goodman $\mathrm{JL}$, Esmon NL et al. Infection of vascular endothelial cells with herpes simplex virus enhances tissue factor activity and reduces thrombomodulin expression. Proc Natl Acad Sci U S A. 1990; 87 (18): 7095-7099.

15. Guan WJ, Ni ZY, Hu Y, Liang WH, Ou CQ, He JX et al. Clinical characteristics of coronavirus disease 2019 in China. N Engl J Med. 2020; 382 (18): 1708-1720. doi: 10.1056/NEJMoa2002032.

16. Giannis D, Ziogas IA, Gianni P. Coagulation disorders in coronavirus infected patients: COVID-19, SARS-CoV-1, MERSCoV and lessons from the past. J Clin Virol. 2020; 127: 104362.

17. Wang W, Tang J, Wei F. Updated understanding of the outbreak of 2019 novel coronavirus (2019-nCoV) in Wuhan, China. J Med Virol. 2020; 92 (4): 441-447. doi: 10.1002/jmv.25689.

18. Rothan HA, Byrareddy SN. The epidemiology and pathogenesis of coronavirus disease (COVID-19) outbreak. J Autoimmun. 2020; 109: 102433. doi: 10.1016/j.jaut.2020.102433.

19. Wang L, Zou A, Wang J et al. Matrix analysis of clinical characteristics and dynamic observation of immunological features in 90 cases of COVID-19. SSRN 2020, published online April 02. 10.2139/ssrn.3556688 [preprint].

20. Assiri A, Al-Tawfiq JA, Al-Rabeeah AA, Al-Rabiah FA, Al-Hajjar $\mathrm{S}, \mathrm{Al}$-Barrak A et al. Epidemiological, demographic, and clinical characteristics of 47 cases of Middle East respiratory syndrome coronavirus disease from Saudi Arabia: a descriptive study. Lancet Infect Dis. 2013; 13 (9): 752-761.

21. Lee N, Hui D, Wu A, Chan P, Cameron P, Joynt GM et al. A major outbreak of severe acute respiratory syndrome in Hong Kong. $\mathrm{N}$ Engl J Med. 2003; 348 (20): 1986-1994.

22. Wong KT, Antonio GE, Hui DS, Lee N, Yuen EH, Wu A et al. Severe acute respiratory syndrome: radiographic appearances and pattern of progression in 138 patients. Radiology. 2003; 228 (2): 401-406.

23. Shi H, Han X, Jiang N, Cao Y, Alwalid O, Gu J et al. Radiological findings from 81 patients with COVID-19 pneumonia in Wuhan, China: a descriptive study. Lancet Infect Dis. 2020; 20 (4): 425-434.

24. Kermali M, Khalsa RK, Pillai K, Ismail Z, Harky A. The role of biomarkers in diagnosis of COVID-19 - A systematic review. Life Sci. 2020; 254: 117788. 
25. Rodriguez-Morales AJ, Cardona-Ospina JA, Gutiérrez-Ocampo E, Villamizar-Peña R, Holguin-Rivera Y, Escalera-Antezana JP et al. Electronic address: https://www.lancovid.org. Clinical, laboratory and imaging features of COVID-19: a systematic review and meta-analysis. Travel Med Infect Dis. 2020; 34: 101623.

26. Velavan TP, Meyer CG. Mild versus severe COVID-19: laboratory markers. Int J Infect Dis. 2020; 95: 304-307.

27. Zhai P, Ding Y, Wu X, Long J, Zhong Y, Li Y. The epidemiology, diagnosis and treatment of COVID-19. Int J Antimicrob Agents. 2020; 55 (5): 105955.

28. Abbasi-Oshaghi E, Mirzaei F, Farahani F, Khodadadi I, Tayebinia $\mathrm{H}$. Diagnosis and treatment of coronavirus disease 2019 (COVID-19): Laboratory, PCR, and chest CT imaging findings. Int J Surg. 2020; 79: 143-153.

29. Shi Y, Wang Y, Shao C, Huang J, Gan J, Huang X et al. COVID-19 infection: the perspectives on immune responses. Cell Death Differ. 2020; 27 (5): 1451-1454.

30. Chen G, Wu D, Guo W, Cao Y, Huang D, Wang H et al. Clinical and immunological features of severe and moderate coronavirus disease 2019. J Clin Invest. 2020; 130 (5): 2620-2629. doi: $10.1172 / \mathrm{JCl} 137244$.

31. Pambuccian SE. The COVID-19 pandemic: implications for the cytology laboratory. J Am Soc Cytopathol. 2020; 9 (3): 202-211.

32. Zhang K, Liu X, Shen J, Li Z, Sang Y, Wu X et al. Clinically applicable ai system for accurate diagnosis, quantitative measurements, and prognosis of COVID-19 pneumonia using computed tomography. Cell. 2020; 182 (5): 1360.

33. Cao X. COVID-19: immunopathology and its implications for therapy. Nat Rev Immunol. 2020; 20 (5): 269-270. doi: 10.1038/ s41577-020-0308-3.

34. Xu Z, Shi L, Wang Y, Zhang J, Huang L, Zhang C et al. Pathological findings of COVID-19 associated with acute respiratory distress syndrome. Lancet Respir Med. 2020; 8 (4): 420-422.

35. Huang C, Wang Y, Li X, Ren L, Zhao J, Hu Y et al. Clinical features of patients infected with 2019 novel coronavirus in Wuhan, China. Lancet. 2020; 395 (10223): 497-506.

36. Hoogduijn MJ, Roemeling-van Rhijn M, Engela AU, Korevaar SS, Mensah FK, Franquesa $\mathrm{M}$ et al. Mesenchymal stem cells induce an inflammatory response after intravenous infusion. Stem Cells Dev. 2013; 22 (21): 2825-2835.

37. Schrepfer S, Deuse T, Reichenspurner H, Fischbein MP, Robbins $\mathrm{RC}$, Pelletier MP. Stem cell transplantation: the lung barrier. Transplant Proc. 2007; 39 (2): 573-576.

38. Fischer UM, Harting MT, Jimenez F, Monzon-Posadas WO, Xue $\mathrm{H}$, Savitz SI et al. Pulmonary passage is a major obstacle for intravenous stem cell delivery: the pulmonary first-pass effect. Stem Cells Dev. 2009; 18 (5): 683-692.

39. Golchin A, Seyedjafari E, Ardeshirylajimi A. Mesenchymal stem cell therapy for COVID-19: present or future. Stem Cell Rev Rep. 2020; $16(3): 427-433$
40. Weiss DJ, Casaburi R, Flannery R, LeRoux-Williams M, Tashkin DP. A placebo-controlled, randomized trial of mesenchymal stem cells in COPD. Chest. 2013; 143 (6): 1590-1598.

41. Krampera M. Mesenchymal stromal cell 'licensing': a multistep process. Leukemia. 2011; 25 (9): 1408-1414.

42. Blander JM. The many ways tissue phagocytes respond to dying cells. Immunol Rev. 2017; 277 (1): 158-173.

43. Bernardo ME, Fibbe WE. Mesenchymal stromal cells: sensors and switchers of inflammation. Cell Stem Cell. 2013; 13 (4): 392-402.

44. Melief SM, Schrama E, Brugman MH, Tiemessen MM, Hoogduijn MJ, Fibbe WE et al. Multipotent stromal cells induce human regulatory $T$ cells through a novel pathway involving skewing of monocytes toward anti-inflammatory macrophages. Stem Cells. 2013; 31 (9): 1980-1991.

45. Di Nicola M, Carlo-Stella C, Magni M, Milanesi M, Longoni PD, Matteucci $P$ et al. Human bone marrow stromal cells suppress T-lymphocyte proliferation induced by cellular or nonspecific mitogenic stimuli. Blood. 2002; 99 (10): 3838-3843.

46. Liang B, Chen J, Li T, Wu H, Yang W, Li Y et al. Clinical remission of a critically ill COVID-19 patient treated by human umbilical cord mesenchymal stem cells: a case report. Medicine (Baltimore). 2020; 99 (31): e21429.

47. Mesoblast. Fase $2 / 3$ ensayo controlado aleatorio de remestemcel-L en 300 pacientes con síndrome respiratorio agudo covid-19 comienza la inscripción. Melbourne, Australia; 30 de abril de 2020; y Nueva York, Estados Unidos; 29 de abril de 2020.

48. https://www.cleveland19.com/2020/05/04/university-hospitalscleveland-biotech-company-athersys-team-up-covid-clinical-trial/ (buscado el 11 de mayo de 2020)

49. Guenther Koehne, M.D., Ph.D., and Javier Pérez-Fernández, M.D., safely administered the new treatment to patients through intravenous infusions of experimental umbilical cord mesenchymal stem cells. Clinical trial being conducted under an emergency approval from the Food and Drug Administration (FDA), Baptist Health Hospitalof Miami. May 4, 2020.

50. https://pipelinereview.com/index.php/2020031374023/DNA-RNAand-Cells/Pluristem-and-Charite-University-of-Medicine-BerlinJoin-Forces-Targeting-Potential-Treatment-for-Respiratory-andInflammatory-Intratissue-Complications-Caused-by-COVID.html. (buscado el 17 de marzo de 2020)

51. FDA Approval to Commence First Mesenchymal Stem Cell Clinical Trial for Protection Against COVID-19. Houston, TX, April 06, 2020-Hope Biosciences.

52. Qu W, Wang Z, Hare JM, Bu G, Mallea JM, Pascual JM et al. Cellbased therapy to reduce mortality from COVID-19: Systematic review and meta-analysis of human studies on acute respiratory distress syndrome. Stem Cells Transl Med. 2020; 9 (9): 1007-1022.

53. www.clinicaltrials.gov

Conflicto de intereses: No hay conflicto de intereses. 